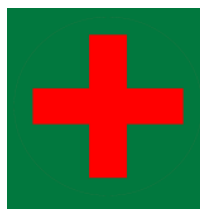

\title{
Analisis Kuantitatif Informed Consent Pada Tindakan Sectio Caesarea di Rumah Sakit Patria IKKT Jakarta Barat
}

\author{
Nurmayantih ${ }^{1}$, Nanda Aula Rumana ${ }^{2}$, Daniel Happy Putra ${ }^{3}$, Puteri Fannya ${ }^{4}$ \\ ${ }^{1,2,3,4}$ Program Studi Rekam Medis dan Informasi Kesehatan, Fakultas Ilmu-ilmu \\ Kesehatan, Universitas Esa Unggul, DKI Jakarta, Indonesia \\ Email: ${ }^{1}$ nurmayantih943@gmail.com
}

\begin{abstract}
Informed Consent is the consent given by the patient or his family on the basis of an explanation of the medical/surgical action to be performed on the patient and this informed consent must be complete. In performing sectio caesarea, the informed consent sheet is not filled in, so any action taken can be categorized as malpractice. Researchers found that there were still many incomplete informed consent forms, especially informed consent for sectio caesarea surgery. The purpose of the study was to determine the quantitative analysis of informed consent for sectio caesarea at the Patria IKKT Hospital for the period March - April 2021 based on 4 components, namely knowing the completeness of patient identification, author authentication, and completeness of important reports, good records. This type of research is quantitative with descriptive design and data collection techniques are observation, checklist. This research was conducted using systematic random sampling method. The results of the study of 90 informed consent sheets for sectio caesarea, the average completeness of the patient identification filling component was $100 \%$, the important component of filling out the report was an average of $86 \%$, the author's authentication component had an average of $97.9 \%$, the component of filling out good notes had an average of $97.9 \%$. the average completeness is $93.7 \%$. The results of the recapitulation of quantitative analysis have an average completeness of $94.4 \%$.
\end{abstract}

Keywords: Informed Consent on Sectio Caesarea Action, Quantitative Analysis.

\begin{abstract}
Abstrak
Informed Consent adalah persetujuan yang diberikan oleh pasien atau keluarganya atas dasar penjelasan tindakan medis/bedah yang akan dilakukan terhadap pasien dan informed consent ini harus lengkap. Dalam melakukan sectio caesarea lembar informed consent tidak diisi, maka setiap tindakan yang dilakukan dapat dikategorikan sebagai malpraktik. Peneliti menemukan bahwa masih banyak formulir informed consent yang tidak lengkap, terutama informed consent untuk operasi sectio caesarea. Tujuan penelitian untuk mengetahui analisis kuantitatif informed consent operasi sectio caesarea di RS Patria IKKT periode Maret - April 2021 berdasarkan 4 komponen yaitu mengetahui kelengkapan identifikasi pasien, autentikasi penulis, dan kelengkapan laporan yang penting, catatan yang baik. Jenis penelitian ini adalah kuantitatif dengan desain deskriptif dan teknik pengumpulan data observasi, daftar tilik. Penelitian ini dilakukan dengan menggunakan metode systematic random sampling. Hasil penelitian dari 90 lembar informed consent tindakan sectio caesarea, rata-rata kelengkapan
\end{abstract}


komponen pengisian identifikasi pasien $100 \%$, komponen pengisian laporan yang penting rata-rata $86 \%$, komponen autentikasi penulis memiliki rata-rata $97,9 \%$, komponen pengisian catatan baik memiliki rata-rata kelengkapan 93,7\%. Hasil rekapitulasi analisis kuantitatif memiliki rata-rata kelengkapan 94,4\%.

Kata Kunci: Informed Consent Tindakan Sectio Caesarea, Analisis Kuantitatif.

\section{PENDAHULUAN}

Rumah sakit merupakan institusi pelayanan kesehatan yang menyelenggarakan pelayanan kesehatan perorangan secara paripurna yang menyediakan pelayanan rawat jalan, rawat inap dan gawat darurat serta penunjang lainnya (KEMENKES RI, 2009). Setiap rumah sakit mempunyai kewajiban, satu diantaranya rekam medis. Rekam medis merupakan file yang berisikan catatan dan dokumen tentang identitas pasien, pengobatan, pemeriksaan, tindakan dan pelayanan lain yang telah diberikan kepada pasien pada fasilitas kesehatan (Kemenkes RI, 2008). Rekam medis harus dibuat secara tertulis, lengkap, dan jelas atau secara elektronik (Kemenkes RI, 2008).

Didalam rekam medis terdapat beberapa formulir yang salah satuya adalah formulir persetujuan tindakan kedokteran atau informed consent. Pengisian informed consent harus diperhatikan karena merupakan suatu bukti tertulis yang sangat penting dalam mendukung aspek hukum rekam medis. Hal ini untuk melindungi pasien atas setiap tindakan yang dilakukan sehingga tidak dikategorikan sebagai malpraktek. Informed consent adalah persetujuan yang diberikan oleh pasien atau keluarga terdekat setelah mendapat penjelasan secara lengkap mengenai tindakan kedokteran atau kedokteran gigi yang akan dilakukan terhadap pasien. Kelengkapan dan ketidaklengkapan informed consent sangat berpengaruh pada mutu pelayanan rumah sakit. Maka dari itu, kelengkapan informed consent harus diperhatikan dengan cara analisis kuantitatif. Analisis kuantitatif adalah telaah atau review bagian tertentu isi rekam medis dengan maksud menemukan kekurangan khusus dari isi rekam medis yang berkaitan dengan pendokumentasian rekam medis. Analisis kuantitatif terdiri dari 4 (empat) komponen yaitu review identifikasi, review laporan yang penting, review autentikasi dan review pendokumentasian yang benar (Widjaja, 2015).

Dalam melakukan tindakan sectio caesarea harus terlebih dahulu mengisi informed consent dengan tujuan bahwa pasien atau keluarga menyetujui tindakan yang dilakukan. Berdasarkan hasil survey pendahuluan dapat diketahui bahwa sectio caesarea merupakan jenis tindakan medis yang paling banyak yang ada di Rumah Sakit Patria IKKT dengan hasil presetase tindakan operasi section caesarean sebesar $80 \%$, sedangkan hasil presentase tindakan operasi lainnya sebesar $20 \%$. Rumah Sakit Patria IKKT beralamatkan di jalan Cendrawasih no.1 RT/RW 05/02, Komplek Kemhan TNI Slipi, Kelurahan Palmerah, Kecamatan Palmerah, Kota Jakarta Barat. Rumah Sakit Patria IKKT merupakan rumah sakit tipe C yang diresmikan pada tanggal 14 Juli 1991.

Berdasarkan hasil penelitian Rusdiana dan Akhyar di RSUP Persahabatan tahun 2017 didapatkan kelengkapan pengisian persetujuan tindakan kedokteran pasien bedah sebanyak 56 sampel, kelengkapan identitas pemberi persetujuan sebanyak $83.92 \%$, pada kelengkapan laporan yang penting sebanyak $67.45 \%$, komponen autentikasi pemberi persetujuan sebanyak $60,26 \%$, dan komponen catatan yang baik sebanyak $67,85 \%$. 
Hasil rekapitulasi dari 4 komponen analisis persetujuan tindakan kedokteran sebanyak 69,87\% (Rusdiana \& Ahyar, 2017). Berdasarkan hasil penelitian Wulandari tentang analisis kelengkapan pengisian informed consent tindakan bedah di Rumah Sakit Pertamina Bintang Amin periode Desember 2018 diperoleh komponen identifikasi kelengkapan pengisian ditemukan pada item nama pasien sebanyak 53,5\%, pada komponen laporan penting kelengkapan 68,5\%, pada komponen kelengkapan pengisian autentifikasi rata-rata sebesar 74,8\%. Secara review keseluruhan lembar informed consent memenuhi kelengkapan sebanyak 23\% (Wulandari et al., 2019).

Berdasarkan hasil observasi awal terhadap 30 lembar informed consent pada tindakan sectio caesarea pada bulan November 2020 di Rumah Sakit Patria IKKT menganalisis 4 komponen, didapatkan hasil identifikasi pasien 97,33\%, kelengkapan laporan yang penting $90,67 \%$, autentikasi penulis $88.8 \%$ dan catatan yang baik $90,18 \%$. Hasil rata-rata kelengkapan informed consent pada tindakan sectio caesarea $91,73 \%$. Hasil tersebut masih belum sesuai dengan standar pelayanan minimal mutu informed consent yang dibuat oleh kemenkes, dimana informed consent harus terisi $100 \%$ (Menkes RI, 2008). Berdasarkan latar belakang permasalahan tersebut, peneliti tertarik untuk meneliti tentang, "Analisis kuantitatif informed consent pada tindakan sectio caesarea di Rumah Sakit Patria IKKT". Adapun tujuan dari penelitian ini mengetahui gambaran kelengkapan informed consent pada tindakan sectio caesarea di Rumah Sakit Patria IKKT berdasarkan 4 kompenen yaitu : mengetahui kelengkapan identifikasi pasien, kelengkapan autentikasi penulis, kelengkapan laporan yang penting, kelengkapan pencatatan yang baik pada formulir informed consent pada tindakan sectio caesarea di Rumah Sakit Patria IKKT.

\section{METODE}

Metode Penelitian yang digunakan adalah metode deskriptif yaitu mengetahui gambarkan kelengkapan informed consent dengan menggunakan analisis kuantitatif di Rumah sakit Patria IKKT. Populasi pada penelitian ini adalah seluruh rekam medis pasien sectio caesarea Rumah Sakit Patria IKKT pada bulan Maret - April 2021 berjumlah 90 rekam medis. Pengambilan sampel penelitian ini dilakukan dengan menggunakan teknik systematic random sampling. Teknik pengumpulan data pada penelitian ini menggunakan observasi pengamatan langsung lembar informed consent pada tindakan sectio caesarea.

\section{HASIL}

Tabel 1. Hasil Analisis Kuantitatif Informed Consent Pada Tindakan Sectio Caesarea di Rumah Sakit Patria IKKT pada Bulan Maret - April 2021.

\begin{tabular}{|c|c|c|c|c|c|}
\hline & \multirow[t]{2}{*}{ KRITERIA ANALISIS } & \multicolumn{2}{|c|}{ LENGKAP } & & KAP \\
\hline & & $\mathrm{N}$ & $\%$ & $\mathrm{~N}$ & $\%$ \\
\hline
\end{tabular}

IDENTIFIKASI PASIEN

Pasien

1. Nama

2. No Rekam Medis

3. Tanggal Lahir

$\begin{array}{llll}90 & 100 \% & 0 & 0 \% \\ 90 & 100 \% & 0 & 0 \% \\ 90 & 100 \% & 0 & 0 \%\end{array}$




\begin{tabular}{|c|c|c|c|c|c|}
\hline 4. & Jenis kelamin & 90 & $100 \%$ & 0 & $0 \%$ \\
\hline \multirow[t]{2}{*}{5.} & Alamat & 90 & $100 \%$ & 0 & $0 \%$ \\
\hline & \multicolumn{5}{|l|}{ Pemberi Persetujuan } \\
\hline 6. & Nama & 90 & $100 \%$ & 0 & $0 \%$ \\
\hline 7. & Tanggal Lahir & 90 & $100 \%$ & 0 & $0 \%$ \\
\hline 8. & Jenis Kelamin & 90 & $100 \%$ & 0 & $0 \%$ \\
\hline 9. & Alamat & 90 & $100 \%$ & 0 & $0 \%$ \\
\hline 10. & Hubungan Dengan Pasien & 90 & $100 \%$ & 0 & $0 \%$ \\
\hline \multicolumn{2}{|c|}{ Average } & 90 & $100 \%$ & 0 & 0 \\
\hline \multicolumn{6}{|c|}{ KELENGKAPAN LAPORAN YANG PENTING } \\
\hline 1. & Diagnosa & 82 & $91,1 \%$ & 8 & $8,9 \%$ \\
\hline 2. & Tindakan Kedokeran & 82 & $91,1 \%$ & 8 & $8,9 \%$ \\
\hline 3. & Indikasi Tindakan & 75 & $83,3 \%$ & 15 & $16,7 \%$ \\
\hline 4. & Tata Cara Tindakan & 75 & $83,3 \%$ & 15 & $16,7 \%$ \\
\hline 5. & Tujuan & 74 & $82,2 \%$ & 16 & $17,8 \%$ \\
\hline 6. & Risiko & 75 & $83,3 \%$ & 15 & $16,7 \%$ \\
\hline 7. & Komplikasi & 75 & $83,3 \%$ & 15 & $16,7 \%$ \\
\hline 8. & Prignosis & 82 & $91,1 \%$ & 8 & $8,9 \%$ \\
\hline 9. & Alternatif \& Risiko & 73 & $81,1 \%$ & 17 & $18,9 \%$ \\
\hline 10. & Dr. Pelaksana Tindakan & 81 & $90 \%$ & 9 & $10 \%$ \\
\hline \multicolumn{2}{|c|}{ Average } & 77,4 & $86 \%$ & 12,6 & $14 \%$ \\
\hline \multicolumn{6}{|c|}{ AUTENTIKASI PENULIS } \\
\hline 1. & Nama Dr & 90 & $100 \%$ & 0 & $0 \%$ \\
\hline 2. & TTD Dr & 90 & $100 \%$ & 0 & $0 \%$ \\
\hline 3. & Nama Bidan & 78 & $86,7 \%$ & 12 & $13,3 \%$ \\
\hline 4. & TTD Bidan & 90 & $100 \%$ & 0 & $0 \%$ \\
\hline 5. & Nama Permberi Persetujuan & 87 & $96,7 \%$ & 3 & $3,3 \%$ \\
\hline 6. & TTD Pemberi Persetujuan & 90 & $100 \%$ & 0 & $0 \%$ \\
\hline 7. & Nama Saksi & 90 & $100 \%$ & 0 & $0 \%$ \\
\hline 8. & TTD Saksi & 90 & $100 \%$ & 0 & $0 \%$ \\
\hline \multicolumn{2}{|c|}{ Average } & 88,1 & $97,9 \%$ & 1,9 & $2,1 \%$ \\
\hline \multicolumn{6}{|c|}{ CATATAN YANG BAIK } \\
\hline 1 & Tdk ada Coretan & 90 & $100 \%$ & 0 & $0 \%$ \\
\hline 2 & Tdk ada Tipp-ex & 90 & $100 \%$ & 0 & $0 \%$ \\
\hline 3 & Tdk ada bag. Kosong & 73 & $81,1 \%$ & 17 & $18,9 \%$ \\
\hline \multicolumn{2}{|c|}{ Average } & 84,3 & $93,7 \%$ & 5,7 & $6,3 \%$ \\
\hline & Total Average & 84,9 & $94,4 \%$ & 5,05 & $5,6 \%$ \\
\hline
\end{tabular}

Berdasarkan Tabel 1 menunjukkan bahwa komponen pengisian kelengkapan identitas pasien rata-rata kelengkapanya sebesar 100\%. Komponen pengisian kelengkapan catatan/form yang penting rata-rata kelengkapannya sebesar $86 \%$, persentase tertinggi kelengkapan catatan/form yang penting terdapat pada bagian diagnose, tindakan kedokteran, prognosis sebesar 91,1\%, sedangkan persentase terendah terdapat pada bagian alternatif \& resiko sebesar $81,1 \%$. Komponen autentikasi penulis 
rata-rata kelengkapanya sebesar 97,9\%, persentase tertinggi autentikasi penulis terdapat pada bagian nama dokter, tandatangan dokter, tandatangan bidan, tandatangan pemberi persetujuan, nama saksi, tandatangan saksi sebesar $100 \%$, sedangkan presentase terendah terdapat pada bagian nama bidan sebesar $86,7 \%$. Komponen pengisian catat yang baik rata-rata kelengkapanya sebesar $93,7 \%$, persentase tertinggi catatan yang baik terdapat pada bagian tidak ada coretan, tidak ada tipp-ex sebesar $100 \%$, sedangkan presentase terendah terdapat pada bagian tidak ada bagian yang kosong sebesar $81,1 \%$.

Hasil rekapitulasi analisis kuantitatif informed consent pada tindakan sectio caesarea dari 90 informed consent yang dianalisis, rata-rata kelengkapannya 94,4\%. Presentase tertinggi kelengkapannya terdapat pada identifikasi pasien sebesar $100 \%$, sedangkan presentase terendah terdapat pada komponen kelengkapan laporan yang penting sebesar $86 \%$. Yang perlu di perhatikan pada bagian alternative dan risiko, tidak ada bagian yang kosong sebesar $81,1 \%$.

\section{PEMBAHASAN}

Berdasarkan hasil penelitian didapatkan analisis kuantitatif komponen identifikasi pasien rata-rata kelengkapanya sebesar $100 \%$. Hasil tersebut sudah sesuai dengan PERMENKES RI No. 129/MENKES/II/2008 tentang Standar Pelayanan Minimal Rumah Sakit yaitu kelengkapan pengisian informed consent harus $100 \%$ (Menkes RI, 2008). Apabila identitas pasien tidak terisi dengan lengkap dapat terjadi kesalahan pasien yang akan dilakukan tindakan atau salah sasaran bahkan menyebabkan malpraktek kedokteran (Aryati dkk., 2018).

Hasil analisis kuantitatif komponen kelengkapan catatan yang penting rata-rata kelengkapanya sebesar $86 \%$. Bagian yang perlu diperhatikan dalam kelengkapan catatan yang penting yaitu alternative dan risiko dengan ketidaklengkapan sebesar 18,9\%. Berdasarkan UU Nomor 29 tahun 2004 tentang Praktek Kedokteran Pasal 45 ayat (3) menyebutkan bahwa informed consent sekurang-kurangnya mencakup : diagnosa dan tatacara tindakan medis, tujuan tindakan medis yang dilakukan, alternatif tindakan lain dan resikonya, resiko dan komplikasi yang mungkin terjadi, prognosis terhadap tindakan yang dilakukan (UU RI Nomor, 2004). Formulir informed consent disimpan di dalam rekam medis pasien dan bila dalam formulir informed consent tersebut tidak lengkap di isi akan mempersulit pihak rumah sakit terutama petugas rekam medis pada bagian pengecekan kelengkapan formulir informed consent apabila kelak pasien menuntut kepada rumah sakit atau dokter jika hasil dari operasi tidak seperti yang diharapkan oleh pasien ataupun keluarga (Octaria \& Trisna, 2016).

Hasil analisis kuantitatif komponen kelengkapan autentikasi penulis rata-rata kelengkapanya sebesar 97,9\%. Bagian yang perlu diperhatikan pengisian pada bagian nama bidan ketidaklengkapannya sebesar $13,3 \%$. Catatan medis yang terdapat dalam berkas rekam medis dikatakan memiliki keabsahan bilamana tenaga kesehatan yang merawat pasien atau surat persetujuan yang diberikan diakhiri dengan membubuhkan atau mengabsahkan tandatangan dan nama terang (Wulandari et al., 2019). Ketidaklengkapan lembar informed consent berdampak pada menurunnya kualitas mutu rekam medis sehingga bisa berpengaruh pada proses penilaian akreditasi rumah sakit, selain itu juga berdampak pada jaminan kepastian hukum bagi pasien, tenaga rekam medis, tenaga medis, maupun pihak rumah sakit. Apabila terjadi sengketa dikemudian 
hari, alat bukti berupa informed consent menjadi kurang kuat akibat tidak jelasnya identitas yang menandatangani baik dari pihak pasien maupun dokter yang menangani pasien (Bedah et al., n.d.).

Hasil analisis kuantitatif komponen catatan yang baik rata-rata kelengkapannya sebesar 93,7\%. Bagian yang perlu diperhatikan dalam catatan yang baik pada bagian tidak ada bagian yang kosong ketidaklengkapannya sebesar 18,9\%. Review catatan yang baik yaitu memastikan pendokumentasian yang benar jika pencatatan jelas dan terbaca, penggunaan singkatan, pembetulan kesalahan penulisan, bila ada baris yang kosong diberi tanda (Rizkika, 2020). Menurut PERMENKES RI No. 269/MENKES/PER/III/2008 tentang rekam medis bahwa rekam medis harus dibuat secara tertulis, lengkap dan jelas atau secara elektronik (Kemenkes RI, 2008).

\section{KESIMPULAN DAN SARAN}

Berdasarkan hasil penelitian yang dilakukan peneliti di Rumah Sakit Patria IKKT dapat disimpulkan bahwa hasil analisis kuantitatif dari 90 informed consent pada tindakan section caesarean : Komponen identifikasi pasien rata-rata kelengkapanya sebesar $100 \%$. Komponen kelengkapan catatan yang penting rata-rata kelengkapanya sebesar $86 \%$. Bagian yang perlu diperhatikan dalam kelengkapan catatan yang penting yaitu alternative dan risiko dengan ketidaklengkapan sebesar 18,9\%. Komponen kelengkapan catatan yang penting rata-rata kelengkapanya sebesar 97,9\%. Bagian yang perlu diperhatikan pengisian pada bagian nama bidan ketidaklengkapannya sebesar 13,3\%. Komponen catatan yang baik rata-rata kelengkapannya sebesar 93,7\%. Bagian yang perlu diperhatikan dalam komponen catatan yang baik pada bagian tidak ada bagian yang kosong ketidaklengkapannya sebesar 18,9\%. Agar dalam pengisian informed consent lengkap dan akurat di Rumah Sakit Patria IKKT disarankan untuk hasil evaluasi analisis kuantitatif dilaporkan oleh panitia rekam medis ke komite medis untuk ditindaklanjuti. Sebaiknya disosialisasikan kepada dokter, agar mengisi bagian alternative dan risiko. Sebaiknya disosialisasikan kepada bidan, agar setiap tandatangan harus membubuhkan nama jelas. Diadakan rapat rutin ke unit kerja maupun pelayanan tentang ketidaklengkapan informed consent agar tidak ada lagi bagian yang kosong, sehingga informed consent dapat terisi dengan lengkap.

\section{DAFTAR PUSTAKA}

Aryati dkk. (2018). IJMS - Indonesian Journal On Medical Science - Volume 5 No. 2 Juli 2018. Indonesian Journal on Medical Science, 5(2), 149-155.

Bedah, P., Tk, S., Reksodiwiryo, I. I. I., Iris, A., \& Andalas, U. (n.d.). Analisis Ketidaklengkapan Pengisian Lembar Informed Consent. 15-24.

Kemenkes RI. (2008). Peraturan Mentri Kesehatan Republik Indonesia No.269 Tentang Rekam Medis (pp. 1-7).

KEMENKES RI. (2009). Undang-Undang No 44 Tahun 2009 Tentang Rumah Sakit 1. $269,1-6$.

Menkes RI. (2008). Menteri Kesehatan Republik Indonesia No 129 tahun 2008 Tentang 
Standar Pelayanan Minimal RS (Vol. 49, pp. 1-55).

Octaria, H., \& Trisna, W. V. (2016). Pelaksanaan Pemberian Informasi dan Kelengkapan Informed Consent di Rumah Sakit Umum Daerah Bangkinang (RSUD Bangkinang). Jurnal Kesehatan Komunitas, 3(2), 59-64. https://doi.org/10.25311/keskom.vol3.iss2.103

Rizkika, M. Y. (2020). Analisis Kuantitatif Kelengkapan Dokumen Rekam Medis Pasien Rawat Inap Dengan Diagnosa Fracture Femur Di RSUD Dr. RM Djoelham Binjai. Jurnal Ilmiah Perekam Dan Informasi Kesehatan Imelda, 5(1), 62-71.

Rusdiana, I., \& Ahyar. (2017). Tinjauan Kelengkapan Pengisian Persetujuan Tindakan Kedokteran Pasien Bedah Rawat Inap Di Rumah Sakit Umum Pusat Persahabatan. Medicordhif Vol. 4/Oktober 2017, 4, 21-38. http://akademiperekammedis.ac.id/jurnal/index.php/medicordhif/article/view/15

UU RI Nomor, 29. (2004). UU No. 29 Tahun 2004 Tentang Praktik Kedokteran. Aturan Praktik Kedokteran, 157-180.

Widjaja, L. (2015). Modul Audit Pendokumentasian Rekam Medis. https://doi.org/10.1590/S1516-18462008000300012

Wulandari, M., Wasono, H. A., Lestari, S. M. P., \& Maitsya, A. N. (2019). Analisiskelengkapan Pengisian Informed Consent Tindakan Beedah Di Rumah Sakit Pertamina Bintang Amin Tahun 2018. Jurnal Ilmu Kedokteran Dan Kesehatan, 6(2), 98-104. https://doi.org/10.33024/jikk.v6i2.2296 